\title{
JOSÉ MARÍA SALAVERRÍA Y LA PROFESIONALIZACIÓN DEL ESCRITOR
}

\author{
RAQUEL SÁNCHEZ GARCÍA \\ Facultad de Geografía e Historia, \\ Universidad Complutense de Madrid
}

\section{INTRODUCCIÓN $^{1}$}

Desde finales del siglo XIX se fue asentando el proceso de profesionalización del escritor en España. Pero sería en la primera parte del siglo siguiente cuando tal proceso se consolidó definitivamente de la mano de la renovación del sector editorial. A ello había contribuido el también lento, aunque progresivo, avance del número de lectores potenciales, propiciado por el desarrollo económico y el incremento de la alfabetización ${ }^{2}$. La segunda mitad del siglo XIX había conocido la proliferación de publicaciones en forma de folletín que habían permitido la lectura a un gran número de personas, directa o indirectamente; además, y aquí se sitúa un hecho especialmente significativo, la presencia en los hogares de elementos de lectura dejó de ser una incidencia esporádica para pasar a convertirse, en el mejor de los casos, en algo intrínsecamente unido a la vida de los españoles. Estos acontecimientos prepararon el impulso que tomaría años después la industria editorial en nuestro país. El afianzamiento de ese colectivo de lectores (precario, desde luego, en relación a otros contextos culturales cercanos) y la diversificación de las actividades editoriales per-

\footnotetext{
${ }^{1}$ El presente trabajo forma parte de un estudio sobre el mundo editorial y literario en Madrid (1900-1931) para el cual la autora ha recibido una beca postdoctoral financiada por la Comunidad de Madrid y la Unión Europea. Dicho estudio se encuadra en el proyecto de investigación «Historia de la edición española contemporánea, 18361936», dirigido por Jesús A. Martínez Martín y realizado en el Departamento de Historia Contemporánea, Facultad de Geografía e Historia (Universidad Complutense de Madrid).

2 A. VIÑAO FRAGO, «Alfabetización y alfabetizaciones», en A. Escolano (dir.), Leer $y$ escribir en España. Doscientos años de alfabetización, Madrid, Fundación Germán Sánchez Ruipérez, 1992, pp. 385-402.
}

Rlit, LXV, 129 (2003), 145-165 
mitieron una mayor capitalización de las empresas y su conversión, en muchos casos, en sociedades anónimas ${ }^{3}$.

De forma paralela se produjo el fenómeno que en este artículo será objeto de estudio. A medida que el sector editorial se fue consolidando, las empresas empezaron a necesitar los servicios de los autores de forma continuada para poder proporcionar las publicaciones que se demandaban. Esto provocó varias consecuencias. Una de ellas fue la ampliación de lo que podríamos denominar la «oferta» de autores, es decir, engrosaron las cifras de los componentes del mundo literario. Una segunda consecuencia fue la multiplicación de publicaciones seriadas en forma de colecciones de relatos y de novelas cortas que satisfacían las demandas de la población y que fueron, a la larga, las que permitieron la subsistencia de muchos de estos autores. Pero tal vez la consecuencia más importante estriba en la fundamental transformación que sufrió la figura del autor en general, y del autor literario en particular.

En siglos anteriores, el escritor se había visto favorecido por el mecenazgo de grandes señores y aristócratas, trabajando para ellos como bibliotecario, profesor o siendo un simple protegido. Las transformaciones del mundo moderno impactaron fuertemente en el sentido que de su labor tenían los propios artistas, de manera tal que con el romanticismo comenzó a desarrollarse un agudo sentido de la individualidad artística y de la originalidad de la creación. En el terreno de lo práctico, estas novedades tuvieron su plasmación en las reivindicaciones que de la propiedad intelectual empezó a promover Victor Hugo con la creación de la primera Asociación Internacional de Artistas y Creadores (A.L.A.I.). La reclamación de lo que al escritor pertenecía por sus obras fue el inicio de la conversión del autor en productor. El proceso no resultó sencillo porque, y dejando al margen las opiniones que acerca de la producción literaria y artística tuviera la sociedad, en él debían confluir las nuevas condiciones de la producción literaria con las elevadas ideas acerca del arte existentes entre los creadores. En otras palabras, para la mayor parte de los escritores, unir la rentabilidad económica a la creación literaria era algo parecido a un sacrilegio ${ }^{4}$.

\footnotetext{
${ }^{3}$ Acerca de la modernización del sector editorial: J. F. BotRel, La diffussion $d u$ livre en Espagne (1868-1914), Madrid, Casa de Velázquez, 1988, y Libros, prensa y lectura en la España del siglo XIX, Madrid, Fundación Germán Sánchez Ruipérez, 1993; H. ESCOLAR, «Editores madrileños a principios de siglo», Madrid, Ayuntamiento de Madrid, Aula de Cultura, 1984, «La edición en la época de Juan Ramón Jiménez», Cuadernos Hispanoamericanos, n. ${ }^{\circ}$ 408, junio 1984, pp. 75-97; H. EscolaR (dir.), Historia ilustrada del libro español. La edición moderna. Siglos XIX y XX, Madrid, Fundación Germán Sánchez Ruipérez, 1996; J. A. MARTínez MARTín (ed.), Historia de la edición española contemporánea, 1836-1936, Madrid, Marcial Pons, 2001.

${ }^{4}$ Acerca de estas cuestiones véase mi artículo titulado «La propiedad intelectual en la España contemporánea, 1847-1936», Hispania (C.S.I.C.), Madrid, vol. LXII/3, n. ${ }^{\circ} 212$, 2002, pp. 993-1020.
} 
En España, la profesionalización del escritor se fue generalizando, como ya se ha dicho, durante la primera parte del siglo XX. Si bien pudiera decirse que autores como Pérez Escrich, Ortega y Frías, Fernández y González y algunos más pudieron vivir ya de su pluma gracias a las novelas por entregas, la moderna figura del autor no aparece hasta después ${ }^{5}$. Por tal entendemos aquel autor que por un lado es consciente de su profesión, es decir, que se siente inserto en la sociedad, desempeñando un papel en ella, en la línea en que José Ruiz-Castillo Basala situaba a Azorín: «...transparecen en Azorín la íntima satisfacción y la defensa de su condición de hombre de letras, clase 'social' que, junto a la de otros creadores artísticos, siempre ha dado más que recibió» ${ }^{6}$. Junto a esto, hallaremos escritores que viven de su pluma como autores de novela, teatro o poesía obteniendo recursos a menudo escasos que se completaban con colaboraciones periodísticas, críticas en revistas, 'traducciones o con otras profesiones. Un tercer aspecto especialmente importante en la contemporánea situación del escritor es lo que se refiere a su papel como intelectual, es decir, a su tarea como crítico o analista de la realidad, como portavoz de determinadas demandas sociales.

En este contexto se sitúa la figura de José María Salaverría, escritor extremadamente consciente de la profesión de literato, que por distintas razones analizó con detenimiento. Su persona tiene un interés especial para este estudio, pues sin ser un autor como Baroja, quien prácticamente pudo vivir de sus novelas durante toda su vida (de forma más o menos holgada), Salaverría hubo de completar sus ingresos como escritor con otras ayudas. Además, en su trayectoria se puede estudiar la carrera del autor que pretendía hacerse un hueco en la sociedad literaria, pues Salaverría, cuyos orígenes humildes le habían dificultado el contacto con el mundo de la literatura, hubo de acercarse a dicho entorno dando una serie de pasos comunes a otros pretendientes. Sus continuadas reflexiones y el carácter autobiográfico de muchos de sus escritos nos ayudarán a entender cómo percibía las circunstancias en las que se halló envuelto y cuáles eran los principales elementos que configuraron la moderna imagen del escritor ${ }^{7}$.

Constituye, por otra parte, un autor significativo pues presenta una tra-

\footnotetext{
${ }^{5}$ Véase a este respecto J. Nombela, Impresiones y recuerdos, Madrid, Tebas, 1976.

6 J. Ruiz-Castillo Basala, Memorias de un editor. El apasionante mundo del libro, Madrid, Fundación Germán Sánchez Ruipérez-Ediciones Pirámide, 1986, pp. 218-219.

${ }^{7}$ Salaverría nació en Vinaroz (Castellón) el 28 de mayo de 1873. Poco después se trasladó con su familia a San Sebastián, donde su padre (que era farero) había sido trasladado. Las necesidades económicas de su familia le obligaron a dejar la escuela por el trabajo. Pese a todo, pudo estudiar por las noches. Tras diversas experiencias laborales, ingresó en la Diputación de Guipúzcoa como delineante. Acerca de Salaverría, véanse los siguientes libros: B. PETRIZ RAMOS, Introducción crítico-biográfica a José María Salaverría (1873-1940), Madrid, Editorial Gredos, 1960, y F. CAUDET ROCA, Vida y obra de José María Salaverría, Madrid, C.S.I.C., 1972.
} 
yectoria algo diferente a la de sus contemporáneos Baroja o Azorín (nacidos respectivamente en 1872 y 1873), con más similitudes, tal vez, a la de Maeztu, cuyos orígenes sociales (muy distintos a los de Salaverría) de poco le sirvieron cuando se hundió la fortuna familiar. Su relación con la generación del 98 fue bastante ambigua, pues si por un lado sentía los problemas nacionales desde perspectivas similares, su ubicación en el mundo profesional le condujo al rechazo de las posiciones críticas, pero escasamente comprometidas, de sus contemporáneos. Esta incomprensión ideológica se plasmó también en la forma en que Salaverría contemplaba cómo los hombres del 98 entendían la carrera literaria y su papel como intérpretes de la sociedad de su tiempo. Hay, desde luego, un matiz de animosidad en sus observaciones estrechamente relacionado con las dificultades que tuvo Salaverría para hacerse un lugar en el mundo de la literatura desde sus humildes orígenes y con la sensación de ser un elemento inadaptado en el mundo literario. Pío Baroja se dio perfecta cuenta de esa cierta antipatía, como consignó en sus Memorias: «En Salaverría notaba, detrás de la sonrisa, la hostilidad; en su primer libro Retratos está velada, pero en los Nuevos retratos y en La afirmación española se muestra evidente» ${ }^{8}$.

La situación en la que Salaverría desarrolló su trabajo literario le condujo a conceder una enorme importancia a la fuerza personal, al autodidactismo, a la lucha en solitario y a la voluntad, que tanto decían echar de menos los hombres del 98, a tenor de lo que han dejado escrito. La vida como tiempo para la acción y la recuperación de uno mismo y de la sociedad desde parámetros constructivos está presente en toda la obra de Salaverría, pero sobre todo en Afirmación española: "Yo confieso haber pecado mucho. Pero yo no me asusto de esa obra nihilista, estúpida acaso, seguramente estéril, porque el pesimismo ciego y mecánico no puede conducir a ninguna clase de éxito o prosperidad. Ha llegado la hora de afirmar» ${ }^{9}$. La confianza en el esfuerzo personal, sin embargo, no pudo poner un velo sobre la amargura que las dificultades habían sembrado en el carácter de Salaverría, como él mismo reconocía ante la prensa: «Para mi, al contrario, la adquisición de dinero ha sido siempre una conquista. Pero tan dramática, que ella, y creo no ser avaro, ha ocupado lo mejor de mi vida, se ha reservado lo principal de mi preocupación y ha puesto un poso de acidez en mi trabajada existencia. Porque interesa decirlo, desde la adoles-

\footnotetext{
${ }^{8}$ P. BAROJA, Desde la última vuelta del camino. Memorias. El escritor según él y según los críticos, Madrid, Biblioteca Nacional, 1944, p. 251.

9 J. M. ${ }^{a}$ SAlaVerría, Afirmación española. Estudios sobre el pesimismo español y los nuevos tiempos, Barcelona, Gustavo Gili, 1917, p. 16. Salaverría acusó a la generación del 98 de tener parte de culpa del pesimismo que se había instalado en España: «La generación del 98 tuvo la amarga virtud del nihilismo; enriqueció el caudal negativo de España y añadió pesimismo al acervo común» (p. 59).
} 
cencia me propuse vivir con dignidad y no deber a nadie nada, ni favores ni dinero. Lo he conseguido, pero a costa de esa dramaticidad» ${ }^{10}$.

\section{EL OFICIO DE ESCRITOR}

Salaverría reflexionó en varias ocasiones acerca de la tarea del escritor, de sus dificultades y escribió repetidas veces sobre el papel del creador en la sociedad. Uno de sus textos más destacados al respecto fue $L a$ intimidad literaria, que apareció publicado en 1919. Salaverría trata de hacer en este libro una especie de 'psicología de la literatura' como él mismo dice, explicando al público cuál es la verdadera realidad del autor. A lo largo de sus páginas, va desplegando una teoría del autor, y por extensión del artista, en la que éste es un ser especialmente sensible, que le hace estar en un plano distinto del de los demás seres humanos. Este plano es lo que denomina el 'tercer sexo', y dedica todo el segundo capítulo a tratar de definir lo que entiende por tal: «El artista, pues, no forma un gremio aparte, ni una corporación distinta, ni una secta o una clase diferente, ni siquiera una raza autónoma; positivamente, si queremos expresar bien la naturaleza del artista, necesitamos recurrir a la noción de sexo, que es lo que verdaderamente diferencia en la vida» ${ }^{11}$. Su objetivo es mostrar que, al margen de las diferencias que establece la sociedad, el artista contiene en si mismo algo más, algo distinto, que procede de su esencia intrínseca, y que no tiene nada que ver con construcciones exteriores. Ese algo que diferencia al artista de los demás es una especial sensibilidad que le conduce irremediablemente a la inestabilidad.

Siguiendo este razonamiento, Salaverría ve en la condición de artista una suerte de patología neurótica: «Puede considerarse la producción literaria como un estado latente de enfermedad, sujeto a alteraciones violentas de fiebre, con exaltadas crisis, alucinaciones y aplanamientos. Estas crisis de dudas y autodisminución suelen decidir más de una vocación o carrera literaria. ¡Cuántos han renunciado antes de tiempo, por no poder superar el aplanamiento y esta terrible, insidiosa duda del propio valer!. Sólo resisten los fuertes, y a veces también los tontos, y los que ya no pueden retroceder porque han hecho oficio de su pluma» ${ }^{12}$. El choque del creador con la sociedad constituye uno de los puntos clave de su explicación de la mentalidad del autor: el artista, por una parte aislado, y por otra inmerso en una sociedad para la que su especificidad no significa nada especial,

\footnotetext{
${ }^{10} \mathrm{~F}$. Gómez Hidalgo, ¿Cómo y cuándo ganó usted la primera peseta?, Madrid, Librería Renacimiento, s.f., p. 176.

11 J. M. ${ }^{a}$ Salaverría, La intimidad literaria, Madrid, Editorial Saturnino Calleja, 1919 , p. 19.

12 Ibidem, p. 55.
} 
desarrolla una serie de comportamientos vanidosos y egocéntricos tratando de llamar la atención: «El histrionismo es necesario, tal vez indispensable, para la carrera del escritor, del artista y aún del sabio...», nos dirá en las primeras páginas de este ensayo. Serán los mismos creadores, incluso, los que inventen el tópico del artista desgraciado, tratando de pasarle a la colectividad la factura de su incomprensión: «El artista no es perseguido por los hombres, sino al contrario. La sociedad no es enemiga del genio, sino que lo busca, y cuando lo halla siente gusto en mimarlo. El verdadero enemigo del artista y del genio... son sus compañeros los otros artistas $\mathrm{y}$ aspirantes al genio». $\mathrm{Y}$ a modo de prueba fehaciente de sus palabras, dedicó un considerable espacio en sus escritos a mostrar la imposible existencia de amistad en el mundo literario, circunstancia que, por cierto, corroboran otras fuentes ${ }^{13}$.

Pese a esta visión bastante negativa del creador artístico, hay en las palabras de Salaverría un intento de manifestar que el desequilibrio del artista viene dado tanto por la confrontación con la sociedad como por su propia sensibilidad, o por su propia vocación que, por otra parte, es lo que le salva de la locura y cuya plasmación en algo real le permite continuar existiendo. En su novela corta El literato, que escribió para la serie 'El Cuento Semanal', nos ofrece una buena muestra de estos pensamientos: «Era escritor por ley de su destino; ya no podría ser nada más que escritor. ¿Cómo contener el turbión de ideas, comentarios, imágenes, sentimientos? Dentro de él se formaba diariamente como un aluvión de aguas ideales que rebasaban de su ser y saltaban fuera por conducto de la pluma; si dejasen de saltar aquellas aguas copiosas, llegaría un momento en que no cupiesen dentro de él y lo anegarían. Se formaba dentro de él una concepción ideológica; una preñez angustiosa e impaciente le embargaba cada día, hasta que se abría en el parto, y entonces sentía una impresión de júbilo y de sosiego. Si ahora quisiera encarcelar el aluvión de su inteligencia, las ideas romperían la cárcel y saldrían como locas.... ${ }^{14}$. Salaverría, inserto en las teorías finiseculares acerca del potencial del hombre fuerte y único (que no es, desde sus teorías, el artista común) busca a aquél que sepa aislarse de la influencia del medio, superándola y superponiéndose a la tiranía de la sociedad o del público.

Será precisamente el público uno de los elementos clave dentro de las

${ }^{13}$ Ibidem, p. 22. Entre dichas fuentes podría ponerse como ejemplo esta cita de Carmen Baroja: «Quien ha vivido entre artistas, hombres de letras, etcétera, sabe la poquísima cordialidad que tenían entre ellos y la falta absoluta de amistad. Es cosa rarísima encontrar dos buenos amigos literatos; el caso de Pío y Azorín es rarísimo. Generalmente no se pueden resistir y en general no se estiman ni como escritores ni como personas» (C. BAROJA Y NESSI, Recuerdos de una mujer del 98, Edición de Amparo Hurtado, Barcelona, Editorial Tusquets, 1998, p. 100).

${ }^{14}$ J. M. ${ }^{a}$ Salaverría, El literato, Madrid, El Cuento Semanal, 1907, s.p. 
ideas que acerca del escritor nos propone Salaverría. En la mencionada narración El literato, el público aparece como el auténtico elemento discriminador de las obras literarias, sea acertado su criterio o no lo sea. Lo único real es el poder del público para encumbrar o derribar autores desde su parcialidad: «El escritor, por el contrario, no es dueño de si mismo, ni se pertenece, ni tampoco le pertenece su renombre; este renombre, y su misma personalidad, no son pertenencias del escritor. El escritor, por consiguiente, si fuese lógico, habría de ser humilde, puesto que es un servidor del público. El público manda en el literato, la fama de éste le pertenece al público; el público es como un rey antiguo, autoritario, que puede quitar y dar mercedes» ${ }^{15}$.

A pesar de estas limitaciones, Salaverría concebía la tarea del escritor como una profesión, sujeta a las esclavitudes ya mencionadas, pero como una labor mediante la que ganarse la vida y a la vez realizar la vocación propia, algo fundamental para evitar el trastorno a la esencia del autor. En otros textos definió con más precisión en qué consistía la profesión de autor: «En cambio, estamos viendo que se acentúa el profesionalismo literario, como la literatura se convierte en una profesión tan definida como la arquitectura o la abogacía. El escritor, desposeído ya de melenas, barbas, chalinas y demás agregados peculiares, va entrando en el régimen social común, de las disciplinas corrientes y universales. Es un hombre a sueldo, por jornal o a destajo, que trabaja todos los días en su taller y sirve los encargos lo mejor que puede, ahora un cuento, en seguida una conferencia, un artículo, un drama. Por tanto, tendrá que someterse a las mismas leyes y obligaciones que los otros hombres; no se le consentirá la postura de niño mimado o de hermoso Lucifer a lo Lord Byron» ${ }^{16}$. El proceso ya no tenía vuelta atrás, y como señalaba Salaverría, al autor ya no le quedaba más opción: «El escritor, completamente domesticado, puede, si eso le gusta, llorar con melancolía los tiempos (Musset, Espronceda) en que era menos profesional y más romántico; hoy tiene por fuerza que reconocer que ha ganado en consideración social... tanto como ha perdido en derecho a lo imprevisto y lo pintoresco. Completamente domesticado» ${ }^{17}$.

Evidentemente, en estas nuevas circunstancias el escritor ha perdido su derecho a la rebeldía y su sentido crítico se ha ido desvaneciendo tan deprisa como se va integrando en el colectivo social como un productor más. Salaverría, que observa el proceso no sin lamentarlo, confirma, por otro lado, un hecho, y es que el autor, desde su asimilación social, puede ya reclamar su propiedad como cualquier otro. De ahí que en uno de sus ar-

\footnotetext{
${ }^{15}$ Ibidem.

16 «La moral del literato», $A B C, 17-3-1928$.

17 J. M. ${ }^{a}$ Salaverría, Instantes. Literatura. Política. Costumbres, Madrid, Espasa Calpe, 1927, p. 83.
} 
tículos para $A B C$ indagara con cierto tono satírico acerca de la concepción que del autor y su labor sostenían algunos contemporáneos. El artículo, cuyo título era «Interpretaciones. ¿Deben regalarse los libros?», comentaba la desfachatez con la que el director de una biblioteca de Montevideo le solicitaba con insistencia el regalo de ejemplares de sus libros.

Sobre la anécdota, Salaverría dejaba notar el hecho curioso sobre el que siempre se ha movido el mundo del libro: su supuesto carácter respetable y el trato que recibían tanto el creador como la obra. Leer sus palabras es tal vez la mejor explicación: «Se ha tratado mucho del libro como materia de explotación. El libro que se edita y no se cobra; el libro que se presta y no se devuelve; el libro que se roba en una casa y se vende al librero de viejo. El libro, por lo visto, es una cosa muy sagrada, a la cual, sin embargo, todo el mundo se cree con el derecho de echarle mano. También se ha hablado mucho de la facilidad y desenvoltura con que algunas personas solicitan de los escritores que les envíen sus libros, perfectamente gratis, para nutrir las bibliotecas públicas o de los Casinos y las Corporaciones particulares. Por lo visto, para la clara percepción económica de esas personas un libro nunca puede ser tan legal y corriente mercancía como un canapé, una alfombra, un estante de madera de roble, una lámpara; después que han pagado religiosamente al tapicero, al ebanista, al lampidario, y tiene instalada la sala de la biblioteca a la perfección, se acuerdan de que necesitan reunir los libros y los pide los piden como gracioso regalo a los autores, es decir, a los propios fabricantes de libros, a los que viven, o pretenden, o deberían vivir, de fabricar libros» ${ }^{18}$. Desde esta perspectiva, la relación del autor con su obra y con el público cambia de forma considerable, pues deja de ser un creador desinteresado de productos intelectuales que al poco pasarán al dominio público para convertirse en un profesional más, que enriquece a la sociedad con el producto de su trabajo.

Por lo que respecta al papel del escritor en la sociedad contemporánea, Salaverría es consciente de que su situación ha cambiado considerablemente. En los tiempos modernos, las opiniones del escritor han alcanzado un eco antes no conocido. Estos fueron, desde luego, los años del asentamiento de la figura del intelectual en nuestro país. Salaverría no podía ser insensible a estas transformaciones, y ya en Afirmación española apelaba a la actividad y a la lucha sobre valores constructivos. Años más tarde, sería preguntado acerca de la misma cuestión y, desde su ideología conservadora, contemplaba al escritor como un sujeto abocado a la acción: «Lo mejor sería que la literatura y el arte se mantuviesen al margen de las inquietudes sociales y políticas. Ése es el ideal, y eso es lo que más nos gusta. ¿Pero es posible?. Con el actual régimen de democracias enardecidas, yo creo que no. [...] Desde que la vida entera de la civilización se hace en la calle y

\footnotetext{
18 «Interpretaciones. ¿Deben regalarse los libros?», $A B C, 17-4-1930$.
} 
por todos, es natural que el escritor se vea arrastrado por la ola de los afanes cotidianos e interesados. Por lo tanto, ya no es cuestión de saber si debemos o queremos; yo creo que no podemos retirarnos a cualquiera especie de torre de marfil. Y el que lo pretenda sufrirá una sanción tácita e ineluctable; la vida pasará a su lado sin reparar en él, y todas su voces y gesticulaciones se perderán el vacío» ${ }^{19}$. Sin embargo, observaba Salaverría en su tiempo que los autores, más que como intelectuales independientes, actuaban como elementos partidistas, servidores de determinadas tendencias políticas. De este modo, echaba en falta la existencia de lo que denominaba «caracteres intelectuales» y que definía como «espíritus capaces de pensar libremente y contra las amenazas del vulgo o las escuelas» ${ }^{20}$.

\section{LA CARRERA LITERARIA}

La trayectoria de los escritores del periodo en el que Salaverría desarrolló su labor fue relativamente similar y respondía, con las peculiaridades de cada biografía, a este esquema general: surgimiento de la vocación literaria, petición de cartas de recomendación de escritores consolidados o periodistas locales, acercamiento al foco cultural más destacado (Madrid, generalmente), presentación en redacciones de periódicos y ámbitos de sociabilidad literarios, publicación de los primeros artículos, aparición de las primeras novelas, éxito, consolidación como escritor (tanto en el periodismo como en la literatura), obtención de premios literarios, traducción de sus obras en el extranjero y, como culminación del proceso, elección como miembro de la Academia de la Lengua. Evidentemente, la mayoría de los escritores no recorrieron todo este trayecto, unos se quedaron en sus inicios y fracasaron, otros se estancaron en alguna de las etapas. Sin embargo, el punto de referencia se hallaba en este esquema apresuradamente enumerado aquí.

El camino emprendido por el propio Salaverría es un ejemplo de la forma de acceso de un escritor desconocido al ámbito literario, aunque su trayectoria presentó algunas particularidades que le permitieron permanecer un tanto al margen y, por tanto, observar el contexto con un mayor distanciamiento. Su biografía nos dice que si bien sus primeros empleos poco tuvieron que ver con el ejercicio de la escritura, siempre procuró estar vinculado a ella de alguna forma. La manera más viable en sus circunstancias fue el periodismo, que llegó a convertirse más adelante, cuando Salaverría pudo vivir de la pluma, en su principal sustento económico (en

\footnotetext{
19 Almanaque literario, publicado por G. DE TORRE, M. PÉrez Ferrero y E. SAlazar CHAPEla, Madrid, Editorial Plutarco; 1935, p. 52.

20 «Disputa entre intelectuales», $A B C, 10-12-1921$.
} 
el apartado siguiente se analizarán las reflexiones que acerca del periodismo en relación con la literatura elaboró Salaverría, pues resultan de gran interés a la hora de estudiar el universo mental del autor contemporáneo).

En 1904, hallándose en San Sebastián Pío Baroja, se encontró con Salaverría, el cual le comunicó su deseo de colaborar en algún periódico madrileño. El objetivo de nuestro autor era darse a conocer en Madrid, pues, pese a la revitalización del ambiente cultural periférico que se había ido produciendo desde finales del siglo XIX, la capital continuaba siendo aún el escenario principal, la plataforma para darse a conocer al resto del país. Baroja le escribió una carta para Julio Burell, director de El Gráfico ${ }^{21}$. Este sistema de recomendaciones solía ser habitual, y casi todos los escritores $\mathrm{y}$ articulistas del momento lo utilizaron para abrirse paso en el mundo del periodismo. Desde el 14 de julio hasta el 1 de octubre publicó Salaverría artículos casi diariamente. Se trataba de una serie de sueltos costumbristas con alguna referencia a la actualidad nacional o local. Poco después (en 1906), y persistiendo en su empeño, Salaverría solicitó a Baroja una nueva carta de presentación para publicar en Los Lunes de El Imparcial, lo que consiguió por medio de la aceptación de López Ballesteros, director del periódico ${ }^{22}$. Fue éste un gran éxito para Salaverría, pues El Imparcial era en aquel entonces el periódico más prestigioso y más solicitado, el sueño para todos los pretendientes de la literatura. El mismo Azorín recibió varias negativas antes de entrar en su nómina ${ }^{23}$. En las páginas de El Imparcial publicó Salaverría una serie titulada «Impresiones de Castilla».

A la vez se le abrieron las puertas de España Nueva, dirigido por Rodrigo Soriano, quien le contrató para que escribiera una crónica diaria durante el verano de 1906 pagándole un duro por artículo. Además, en la redacción de España Nueva tuvo la oportunidad de conocer a Pérez Galdós, quien le alabó por sus artículos sobre Castilla en El Imparcial, comprometiéndose a escribirle el prólogo y a buscarle editor si se decidía a publicarlos en forma de libro ${ }^{24}$. El libro, que se iba a titular Vieja España, apareció en el mismo año de 1907, y después de El perro negro (publicado en 1906), era el segundo de los libros de Salaverría. Al año siguiente, logra un contrato con $A B C$, que se mantendrá de forma ininterrumpida hasta 1940.

${ }^{21}$ P. BAROJA, Desde la última..., pp. 244-245.

${ }^{22}$ En sus memorias, Baroja acusa de desagradecido a Salaverría: «Estos pequeños favores yo los agradezco más que los elogios. Sin embargo, he visto que Salaverría en su libro Retratos no los ha señalado, y es más: a lo último, lo que habla de mi es con un fondo más agresivo que otra cosa», P. BAROJA, Desde la última..., p. 245.

${ }^{23}$ «Llegar a la cumbre era cosa dificilísima. Sólo llegaban algunos felices mortales. La cumbre de la fama periodística, en aquellos tiempos, era El Imparcial. Diario de más autoridad no se habrá publicado jamás en España...», Azorín, Valencia. Madrid, Madrid, Alfaguara, 1998, p. 309.

${ }^{24}$ J. M. ${ }^{a}$ SAlaVERría, Nuevos retratos, Madrid, Renacimiento-CIAP, 1930, pp. 9-12. 
Fueron estos tiempos duros en los que el autor tuvo que trabajar a conciencia para hacerse un lugar, años que él mismo consideró más tarde como un importante momento en su aprendizaje: «Escribir mucho, publicar mucho, ver su firma al pie de las columnas tipográficas; con esta impaciente fecundidad, el escritor novel va expulsando todos los excesos ideológicos y sentimentales en la primera, se purga de los atracones emocionales de los verdes años, libra a su estilo de hojarascas o de incoherencias y puede, así, pasar al segundo grado de su carrera en una mejor disposición técnica y espiritual» ${ }^{25}$. Posteriormente, se amplió el número de los periódicos en los que colaboraba Salaverría: desde 1914 hasta 1936 en La Vanguardia, de Barcelona; de 1920 a 1936 en El Pueblo Vasco, de Bilbao; de forma esporádica, pero frecuente desde 1914 hasta 1940 en La Nación, de Buenos Aires; durante los años veinte en el Diario de la Marina, de La Habana; y en la guerra, en España y El Heraldo de Aragón.

Volviendo de nuevo a sus inicios, comprobamos cómo la carrera profesional de Salaverría se asienta primero en el mundo del periodismo, y desde él se proyecta a la literatura. En 1904 aún. vive Salaverría en San Sebastián, aunque una comisión que le encargó la Diputación de Guipúzcoa en su calidad de delineante le permitió pasar una temporada en Madrid, que aprovechó para intentar penetrar en el ambiente literario de la capital con objeto de darse a conocer. Sin embargo, las dificultades fueron considerables pues sus contactos influyentes eran mínimos, a lo que había que unir una limitadora carencia de habilidades sociales en su persona, que él mismo reconocía: «No sé hablar ni exhibirme, no sé murmurar, no digo gracias, soy tardo en comunicarme y tengo el trato social muy solemne y en la amistad al estilo corriente creo que soy insípido» ${ }^{26}$. Este tipo de relaciones sociales resultaban fundamentales para los autores, pues les permitían entrar en los círculos literarios, conocer a los editores, disponer de amistades influyentes y bien relacionadas. Para alguien que procedía de un ambiente ajeno a la literatura, como Salaverría, el ingreso en estos cenáculos era, si cabe, más apremiante.

Como tantos memorialistas de la época nos relatan, se solía llegar a estas tertulias presentado por algún asistente habitual a las mismas, y una vez allí, los escritores nuevos trataban de hacerse notar de la forma en que les era posible: mediante frases ingeniosas, atavíos extravagantes u opiniones extremadas. En esta primera incursión, Salaverría procuró «observar todo cuanto más pude», aunque su disgusto ante lo contemplado le llevó la siguiente conclusión: «Para evitar todo eso, lo único cuerdo que podría

\footnotetext{
${ }^{25}$ Ibidem, p. 9.

${ }^{26}$ Carta de Salaverría a Unamuno fechada en Madrid el 17 de diciembre de 1904, en J. I. TelleCheA Idígoras, Miguel de Unamuno y José María Salaverría. Epistolario (1904-1935), San Sebastián, Fundación Social y Cultural Kutxa, 1995, p. 28.
} 
hacer un literato es nacer rico. El no serlo es mi mayor tormento», así le escribió a Unamuno el 16 de marzo de 1905, habiendo regresado ya a San Sebastián. Se halla ahí una de las semillas que movió tanto la obra como la trayectoria personal y profesional de Salaverría: la búsqueda de la independencia a toda costa. Salaverría trabajó duramente en el mundo del periodismo para poder actuar con libertad en el literario, para depender lo menos posible de cualquier persona que no fuera él mismo, como reconocía en su libro Instantes: «...los escritores no tienen costumbre de avistarse con esa propiedad que se llama independencia. ¡Viven sujetos a tantas servidumbres!. Empiezan por abanderarse en un partido político; acatan la autoridad de una doctrina y de unos capitanes... Yo, por ejemplo, me sostengo a mi mismo, lo cual resulta una faena de veras comprometida. Necesito, como no soy pieza de andamio, sostenerme en el aire en equilibrio y cargando todo el peso de mi persona sobre mi pluma. Ya se desprende que esto ha de tener alguna compensación. La independencia. La libertad del disparo, como los francotiradores» ${ }^{27}$.

Salaverría escribió estas palabras para defenderse de los ataques recibidos por su libro Retratos, en el que había vertido duras críticas hacia las actitudes prepotentes de algunos escritores consolidados como el mismo Unamuno. Desde su perspectiva, el no deber nada a nadie le permitía actuar como crítico literario con total independencia de criterio. Salaverría acusaba al mundo literario nacional de ser demasiado timorato en sus análisis. Desde su punto de vista, en un contexto en el que cada vez se publicaban más libros, se hacía urgente la presencia de críticos que permitieran al lector establecer algún tipo de discriminación entre la multitud de obras colocadas en los estantes de las librerías. Sin embargo, la situación de dependencia de los mismos críticos impedía que su labor fuera más allá de la recomendación efusiva del autor igualmente dependiente, o el ataque a conciencia del escritor perteneciente a una camarilla contraria: «La labor crítica - hay que darle algún nombre- de la camaradería pertenece, al fin y al cabo, a la sección comercial de la industria del reclamo» ${ }^{28}$. Estas observaciones podrían achacarse al aislamiento de Salaverría si no se repitieran en otros especialistas como Enrique de Mesa, reputado crítico teatral, que señalaba en una entrevista realizada en 1927 las dificultades para llevar a cabo su trabajo de forma independiente: «Se ve uno preso entre compromisos [...]. Vendrían abajo casi todos los valores que han alcanzado nombradía de serios» ${ }^{29}$.

El hecho de no encontrar en los cenáculos literarios su lugar ideal, no

${ }^{27}$ J. M. a Salaverría, Instantes, pp. 169-170.

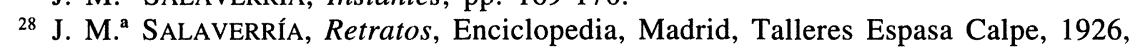
p. 20.

${ }^{29}$ A. CAMín, Entrevistas literarias, edición de J. L. García Martín, Gijón, Llibros del Pexe, 1998, p. 252. 
quiere decir que Salaverría desdeñara esos ámbitos de sociabilidad y no valorara el papel del café o de la tertulia en la configuración del mundo social del escritor. De hecho, dedicó varios artículos periodísticos a ello, entendiéndolo como un elemento peculiar que caracteriza al creador en nuestro país: «Sí; el café recoge propicio la buena tradición española. En su ámbito se descorren, se manosean y, naturalmente, se urden las noticias que los periódicos no pueden acoger, y ya los verdaderos periodistas no están en las redacciones, sino en los cafés» ${ }^{30}$. Su crítica se circunscribe a la superficialidad del mundo literario y la volatilidad de sus alianzas: «...en mi paso por Madrid supe cuán anárquica es esa República de las Letras, cuán rematadamente anárquica: comprendí que no había ningún lazo común, ningún lazo nacido de sincera simpatía y menos aún nacido de un ideal colectivo, de una general aspiración o espíritu de clase. Por eso, pues, todo lo que se cimente sobre un deseo platónico, todo lo que tienda a hermanar generosa y libremente a esos literatos caerá sin remedio. Para hacer algo práctico se necesitaría obrar por grupos sólidos y reducidos, bien compenetrados por una misma aspiración, un idéntico plan y un recíproco respeto; y obrar con energía y violencia $»^{31}$. Para entender plenamente las palabras de Salaverría no hay que olvidar su idea del artista como ser desequilibrado, descentrado, atenazado por los nervios que le produce la difícil adaptación a la sociedad: «Después volvió el pensamiento hacia los escritores, sus compañeros de fatiga. Los vio endebles de salud, llenos de histerismo, atormentados por la envida, decepcionados, irritados contra su suerte, incapaces de abrazar la vida con abrazo viril, sin energía, sin voluntad, nerviosos e intranquilos, sensibles a la menor impresión, pobres, con grandes ambiciones y sin ninguna acción vigorosa en el mundo de los negocios, del amor, de nada. Desgraciados seres que se reunían en algún rincón de la ciudad para hablar de sus grandezas imaginarias o para contar, en un contraste ridículo, el dinero que cobraban o el que cobrarían, el destino que poseerían, el personaje político que los protegería...» ${ }^{32}$.

En el camino del escritor hay otros jalones que cobran importancia a medida que la situación de éste se va asentando en el mundo literario. Se trata de los premios literarios y del acceso a la Real Academia de la Lengua. Salaverría reflexionó acerca de ellos en su libro Instantes, en el que se hacía eco de las transformaciones producidas en el mundo literario desde principios del siglo Xx hasta el momento de publicación de esta obra, 1927. Estos años fueron de especial trascendencia para la transformación del mundo editorial español, el cual se amplió enormemente, surgiendo

\footnotetext{
${ }^{30}$ «El café y su filosofía», $A B C, 14-11-1924$. Véase también «Responso al café en ruinas», $A B C, 8-7-1933$.

${ }^{31}$ Carta de Salaverría a Unamuno fechada en San Sebastián el 14 de mayo de 1905, en J. I. Tellechea Idígoras, op. cit., p. 43.

${ }^{32}$ J. M. ${ }^{a}$ SAlaverRía, El literato, s.p.
} 
multitud de editoriales y colecciones que permitieron que cada vez más autores pudieran vivir de la pluma. Si bien la situación no era comparable a la de otros países como Francia o Inglaterra, desde luego, sí es evidente que en este periodo se incrementó el número de potenciales lectores y la capitalización de las empresas, lo que favoreció el lanzamiento de mayores tiradas (abaratando el precio) de colecciones populares. Novelas cortas que recogían el espíritu de los folletines decimonónicos y los adaptaban a los nuevos tiempos. Sobre esta ampliación de la base del mundo literario y editorial, se fueron instalando otros elementos como los premios y las listas de autores más vendidos o recomendados.

Salaverría censuró lo que de comercial tenían la mayor parte de estas innovaciones en el terreno editorial, señalando «Pero los premios literarios, forma de la burocracia nacional referida a la literatura, acaban siempre en lo inexcusable: beneficencia y cuquería. ¿premio al mérito?. ¿Estímulo a los luchadores?... ¡Pero si siempre son los mismos a disputarse y a escamotear los premios. (Los premios en metálico, naturalmente). Hay media docena de escritores a quienes se puede titular de concursistas» ${ }^{33}$. Probablemente no le faltase razón, pues hasta él mismo se vio solicitado para que promocionase a algunos autores desde la prensa ${ }^{34}$.

Salaverría contemplaba con desorientación las novedades que surgían en el mundo editorial y si su defensa del escritor como profesional de las letras se había convertido para él en una bandera, le resultaba difícil, sin embargo, comprender las consecuencias inherentes a esta transformación: «Cada vez más 'profesionales', los escritores remedan a los políticos del régimen parlamentario o a los hombres de negocios en eso de la propaganda, de la exhibición, el retrato en las revistas, de la interviú, de las revelaciones íntimas, del reclamo a toda vela» ${ }^{35}$. Mientras tanto, observaba sorprendido las actitudes de los jóvenes escritores, con su visión comercial y, como solía decir Salaverría, americana. Comentando el lanzamiento de la Gaceta Literaria, escribía nuestro autor que la nueva revista: «Se pone a tono con la época (fútbol, universalismo, ostentación juvenil, escorzos políticos) y arrostra valientemente la responsabilidad del cartel pegado en las vallas». Sus objetivos se movían dentro de los parámetros de la «industrialización de la literatura»: «Venderle baratos los artículos a la muchedumbre, como se vende un diario de noticias. Hacer multitudinaria la literatura». Sin despreciar este acercamiento al público, Salaverría manifiesta su asombro de que a la vez haya un distinto tipo de lectores para otras publicaciones: «Mientras tanto [...] sale la revista Residencia, correc-

\footnotetext{
${ }^{33}$ J. M. ${ }^{a}$ Salaverría, Instantes, p. 105.

${ }^{34}$ Carta de María Martos a J. M. ${ }^{\text {a }}$ Salaverría en relación a un libro de su marido Ricardo Baeza, fechada en Madrid el 5 de noviembre de 1931, Biblioteca Nacional, Mss. $22605^{120}$.

35 J. M. ${ }^{a}$ SALAVERría, Instantes, p. 137.
} 
tamente trajeada, con un estilo entre inglés y español. La revista Residencia es todo lo contrario de la Gaceta literaria. Sin embargo, ¿cómo es que ambas resultan igualmente modernas y responden a la misma necesidad del momento actual español?» ${ }^{36}$.

La Academia era el reducto final de un escritor tras una carrera profesional brillante. Tradicionalmente, la Academia había estado reservada a los nobles ilustrados del siglo anterior o a autores consagrados pero «respetables», de ahí que desde la generación del 98, para los nuevos autores la Academia no representara nada más que lo convencional, lo establecido. Sin embargo, el ingreso de Azorín en la misma pareció cambiar esta percepción. Azorín, gran detractor de la institución y de lo que en el terreno de la literatura representaba, había sido aceptado en 1924. A partir de este momento, la Academia quedó incluida en el punto de mira de todo escritor que se preciara. Salaverría, que no llegó a entrar en la Academia, se hacía eco de este cambio, señalando sorprendido la novedad: "Y se ha revelado además un fenómeno que permanecía oculto, a saber: que todos los escritores desean ser académicos... Secreto verdaderamente asombroso por la manera cómo ha podido guardarse, pues todo el mundo creíamos que los literatos que estiman en algo su facultad de creación seguían considerando la Academia como el terrible y melancólico premio que se otorga al que ya no sirve para nada» ${ }^{37}$.

Existe, por último, un elemento clave en la carrera literaria de los escritores y es la relación con los editores. A este respecto, muchas fueron las situaciones: desde autores que se autoeditaron una gran parte de sus obras (Valle-Inclán o Juan Ramón Jiménez, por ejemplo), hasta los que fueron tutelados por su editor ${ }^{38}$. La importancia de los editores sobre los autores no es un elemento de menor importancia, pues la mayor parte de las veces eran (y continúan siendo) ellos los que imponen las condiciones de publicación: páginas, tiradas, etc. Salaverría no fue autor de un solo editor. Aunque tuvo amistad profunda con algunos, sus libros se diseminaron por diversas firmas. Las razones habría que buscarlas tanto en el sentido de independencia de nuestro autor y sus dificultades para admitir el tutelaje de nadie, como en su existencia viajera, que le llevó a instalarse en distintos lugares de España y del mundo ${ }^{39}$. Su libro Vieja España salió

36 «La literatura por las calles», $A B C, 30-12-1926$.

37 J. M. ${ }^{a}$ SALAVERRÍA, Instantes, pp. 88-89.

${ }^{38}$ Es muy interesante, por poner un ejemplo, el caso de Jardiel Poncela. Véase al respecto mi artículo «Enrique Jardiel Poncela y el editor José Ruiz Castillo», en Pliegos de Bibliofilia, Madrid, n. ${ }^{\circ} 15,2001$, pp. 3-18.

${ }^{39}$ En 1911 Salaverría marchó a Argentina donde permaneció varios años trabajando como periodista. A su regreso a Europa, emprendió un periplo por varios países europeos como corresponsal de guerra. Posteriormente realizó diversos viajes durante temporadas más o menos prolongadas: Marruecos (1922), Francia, Alemania y Suiza (1923), 
a la luz con la ayuda de Pérez Galdós, que se encargó de buscarle un editor en la casa de Hernando. El año anterior, 1906, había publicado en la Librería de Fernando Fe su primera obra: El perro negro. Cuando su nombre se fue haciendo más sonado, recibió la acogida de editoriales que, como Renacimiento, se encontraban en su momento más pujante.

Con Renacimiento daría a la luz Las sombras de Loyola (1911) y entablaría amistad con el editor José Ruiz-Castillo, que en ese momento dirigía la empresa con Gregorio Martínez Sierra. Con éste, como con otros libros suyos tuvo que hacer Salaverría lo que tanto detestaba y que, por otra parte, se iba a convertir en norma en el contexto editorial contemporáneo. Cuando se publicó el libro, Salaverría ya se había marchado a Argentina, por lo que de la publicidad del libro en España se encargaría la editorial. Sin embargo, el mercado americano, básico para los editores españoles, no podía ser olvidado, y Ruiz-Castillo no iba a dejar pasar la oportunidad de promocionar la editorial teniendo a uno de sus autores en Buenos Aires, de modo que le pidió lo siguiente: «Hoy le mando en un paquete los últimos libros que hemos publicado y así haré en lo sucesivo, esperando que Ud. nos haga la merced de bombeárnoslo en esa prensa, o procurar que nos los bombeen. Para ello le envío también el mismo paquete unas cuantas gacetillas» ${ }^{40}$. Volvió a trabajar con Renacimiento y con la editorial que Ruiz-Castillo creó más tarde, Biblioteca Nueva, bajo cuya rúbrica aparecieron obras como El espíritu ambulante (1920). También lo haría con el editor catalán Gustavo Gili (La afirmación española, 1917), con Saturnino Calleja (La intimidad literaria, 1919), con Rafael Caro Raggio (En la vorágine, 1919), con Espasa Calpe (Instantes, 1927), etc. Mantuvo tratos con la Sociedad General Española de Librería para la distribución de alguna de sus obras, aunque cuando ésta decidió cambiar su sistema de funcionamiento, limitando sus compras a las peticiones en firme, se distanció de ella (al igual que se vieron obligados a hacer, en mejores o peores condiciones, gran parte de los escritores y editores del momento $)^{41}$.

Las novelas y ensayos mencionados proporcionaron a su autor escasos beneficios económicos, por lo que se acercó a las colecciones de relatos cortos, tan populares en su tiempo, para completar los ingresos que obtenía de la prensa. Salaverría no fue uno de los grandes vendedores de esta modalidad de publicación, pero sí gozó de la suficiente acogida como para

América (1927), Portugal (1929), Venezuela y Puerto Rico (1929), Cuba y los Estados Unidos (1931), Noruega, Suecia y Dinamarca (1935).

${ }^{40}$ Carta de José Ruiz-Castillo a José M. ${ }^{a}$ Salaverría, fechada en Madrid el 12 de enero de 1911, Biblioteca Nacional, Mss. 22602118.

${ }^{41}$ Carta de José M. ${ }^{\text {a }}$ Salaverría a José Ruiz-Castillo, fechada en San Sebastián el 14 de septiembre de 1922, Biblioteca Nacional, Mss. $22602^{113}$. 
que sus relatos fueran aceptados en varias colecciones ${ }^{42}$. Comenzó publicando en 'El Cuento Semanal' relatos como El literato, Mundo subterráneo o Nicéforo el tirano; más tarde, colaboraría con 'La Novela Semanal' (Final de drama, Un sacrificio en la selva, entre otras), 'La Novela de Hoy' (El vagabundo inapetente), 'Los novelistas' (El capitán fantasma), etc. También fueron leídos por el público sus relatos aparecidos en diversas revistas y periódicos como Los Lunes de El Imparcial (La hermana Magdalena), La Esfera (La confesión de Julia) o Blanco y Negro (El misterio de la casa rosada). La mayor parte de estos relatos fueron después reunidos formando libros, y así surgieron: Páginas novelescas (1920), El muñeco de trapo (1927) y El libro de las narraciones (1936). También trató Salaverría de probar suerte en el teatro, género para el que escribió varias obras que llegaron a estrenarse, aunque sí se publicaron algunas de ellas, como La flor de Magdala (incluida en Páginas novelescas, 1920) o Guerra de mujeres (Colección Enciclopedia, 1921).

\section{EL ESCRITOR Y EL PERIODISMO}

Como se ha dicho repetidas veces, Salaverría encontró en el periodismo el mejor modo de ganar su sustento y el de su familia. Sin embargo, y al igual que otros autores también dedicados al diario artículo, su consideración acerca de la prensa no era demasiado grata. En el mundo literario se pensaba que un buen escritor no se hacía en el periódico, y que incluso, la tiranía de la colaboración diaria podía llegar a acabar con la obra potencial de los autores con talento. En esta línea iban las recomendaciones que Unamuno hizo a Salaverría durante los primeros años como escritor del segundo poniéndole como ejemplo a Maeztu: «Resístase a entrar en una redacción y malgastar su espíritu en artículos. Esto hace al espíritu fragmentario y le obliga a vivir al día. Mírese en Maeztu. Éste un hombre tan bueno como inteligente, y usted sabe cuán inteligente es, sincero, ingenuo, honrado, lleno de entusiasmo y en quien se suceden las exaltaciones y los desmayos. Pues ya le tiene usted de periodista, dando su espíritu gota a gota, entre espléndidos vislumbres que se olvidarán y ráfagas geniales que alumbran un día a sus lectores. Y él pudo hacer frente a una obra fuerte, sana, espléndida» ${ }^{43}$.

De la misma opinión que Unamuno fueron otros autores como, por ejemplo, Valle-Inclán, quien veía en la prensa el mayor enemigo de la literatura: «Porque estoy convencido de que la colaboración en periódicos

\footnotetext{
${ }^{42}$ L. FERNÁNDEZ CIFUENTES, Teoría mercado de la novela a España: del 98 a la República, Madrid, Gredos, 1982, p. 275.

${ }^{43}$ Carta de Unamuno a Salaverría fechada en Salamanca el 1 de enero de 1904, en J. I. Tellechea IDÍGORAS, op. cit., p. 31.
} 
perjudica grandemente a los escritores. El lector por los periódicos se orienta acerca de cómo piensa y siente el escritor, esto aminora su curiosidad... e impide que compre los libros» ${ }^{44}$. Incluso Azorín, muy vinculado al mundo de las redacciones, ponía en boca de su protagonista en La voluntad estas palabras: «El periodismo ha sido el causante de esta contaminación de la literatura. Ya casi no hay literatura. El periodismo ha creado un tipo frívolamente enciclopédico, de estilo brillante, de suficiencia abrumadora. Es el tipo que detestaba Nietzsche: el tipo 'que no es nada, pero que lo representa casi todo'. Los especialistas han desaparecido: hoy se escribe para el periódico, y el periódico exige que se hable de todo» ${ }^{45}$.

Al igual que con la psicología del escritor, Salaverría reflexionó en varias ocasiones acerca del papel del periodismo y su ejercicio para la vida del escritor y para la época en que éste vive. Sus observaciones presentan matices interesantes respecto de las aportadas por los autores mencionados más arriba. En sus textos sobre la sociedad contemporánea, apuntaba la capacidad del periódico para captar con rapidez las nuevas tendencias sociales y para responder a las demandas del público interesado en asuntos concretos y de actualidad. De este modo el periódico se ha convertido en el medio del que se sirven los que, intelectualmente, pretenden comunicar algo a sus semejantes: «Todos los escritores españoles contemporáneos, los mismos especialistas de las ciencias, los profesores, los médicos y los filósofos; todos los que tienen algo que decir o enseñar afluyen actualmente al periodismo» ${ }^{46}$.

Por otra parte, y en relación al libro, el periódico se adapta mejor a lo que Salaverría denominaba «civilización del tanto y cuanto» (En la vorágine, 1919), es decir, al mercado y sus demandas. El periódico es capaz de pagar al escritor como no lo hace el libro y, por ende, puede dar a conocer su nombre más fácil y rápidamente. El periódico llega a cualquier parte, y su precio es asequible a casi todos; su capacidad de difusión es, por tanto, la clave de su éxito. Además, en una sociedad avasalladora, veloz, que vive apresuradamente, el artículo fugaz llena la efímera necesidad de información del lector, que dispone de poco tiempo para profundizar: «En suma: el periódico se ha montado en España sobre el libro, y ha llegado casi a inutilizarlo. El único órgano de cultura que prácticamente existe hoy en nuestro país es el periódico. ¿Qué resultado producirá el hecho?» ${ }^{47}$. El impacto del periódico y sus formas de acción sobre la literatura han sido, por lo tanto, elemento de primera magnitud a la hora de analizar ésta. Ya no existe un predominio del libro, sino que la «civilización del tanto y

${ }^{44}$ R. M. ${ }^{a}$ DEL VAlle-InCLÁN, Entrevistas, Madrid, Alianza Editorial, 2000, p. 152 (entrevista para La Tribuna, Madrid 16-2-1922).

${ }^{45}$ Azorín, La voluntad, Madrid, Editorial Castalia, 1989, pp. 195-196.

46 J. M. ${ }^{a}$ SAlaVerría, Instantes, p. 14.

${ }^{47}$ Ibidem, p. 128. 
cuanto», lleva consigo la «civilización periodística». Señalaba Salaverría que «La propagación del periodismo industrial ha dado un matiz diferente a la literatura, desde luego, ha formado completamente el tipo de escritor de oficio, que vive sólo de su pluma en calidad de asalariado», y precisaba más adelante: «Pero el periódico, monstruo industrial [...] realmente se apodera del escritor y le hace su vasallo, dándole incluso una personalidad literaria genuina: la de articulista» ${ }^{48}$.

Todas estas observaciones, que pudieran parecer negativas en principio, no acaban de dejar claro el pensamiento de Salaverría al respecto, pues no podía dejar de reconocer la oportunidad que para él mismo supuso la práctica del periodismo, como forma de vida y como forma de ejercer la literatura: «Pero tiene grandes compensaciones, mayores todavía que el autor dramático. El articulista que ha conseguido la publicidad asidua y el afecto del público recibe deleites inefables. Se pone en contacto directo y cordial con el público, lo interesa, lo sugestiona, lo esclaviza; hay una corriente simpática entre el autor y el lector; se crea en el lector un vicio, y verdaderamente, el día en que falta el artículo estimado, el diario resulta fofo ${ }^{49}$. De hecho, Salaverría se convirtió, si no en una figura literaria renombrada, sí en una de las firmas periodísticas más destacadas de su época. Por otra parte, y como él mismo reconocía, el artículo de periódico en España tenía sin duda un impacto tanto mayor cuanto menor era el del libro: «En cuanto a la utilidad del artículo de periódico en la vida moderna, yo creo que es esencialísima, sobre todo en un país como el nuestro, en que la gente no se inclina precisamente a la lectura del libro» ${ }^{50}$.

\section{CONCLUSIONES}

La modernización de la industria editorial española condujo a una necesaria transformación de la mentalidad del autor, que pasó de concebir su tarea desde una perspectiva meramente artística a tomarla como una profesión. El profesionalismo, sin embargo, implicaba una mercantilización del trabajo literario que sonaba un tanto extraña a la mayoría de los escritores. El proceso había comenzado ya antes de los cambios producidos en el sector en el primer tercio del siglo XX con la redacción de artículos para la prensa y con la novela de folletín en la segunda mitad del XIX, pero en el periodo que se ha analizado aquí alcanzó a la considerada «literatura seria». Dicha transformación obligaba al autor a participar en la promoción de su obra, a competir en premios e instituciones, a producir con una determinada regularidad y a adaptarse a las demandas del público. La tran-

\footnotetext{
${ }^{48}$ J. M. ${ }^{a}$ SalaverríA, Retratos, pp. 10-12 y 14.

49 J. M. ${ }^{a}$ SAlaVerRía, La intimidad literaria, p. 122.

50 «El arte del artículo», $A B C, 10-3-1940 »$.
} 
sición no resultó fácil para la mayoría de los escritores y el caso de José María Salaverría es buen ejemplo de ello.

Salaverría, como se ha visto en las páginas antecedentes, se encuentra a caballo entre dos formas de entender el trabajo del escritor: como artista y como profesional de las letras. Por sus circunstancias personales, se convirtió en un profesional de la pluma, que vivía de sus escritos; por sus concepciones acerca de la creación artística como una tarea agónica e incomprendida, Salaverría sostuvo posturas que le aproximaban a la idea romántica del artista. En Salaverría vemos representado el conflicto que atenazaba a tantos otros autores, conflicto que para algunos fue especialmente duro. Gabriel Miró representaría este caso. Para otros, por el contrario, supuso la manera más viable de rentabilizar sus ocupaciones (Ramón Pérez de Ayala) o de financiar otras iniciativas (Jardiel Poncela, quien gracias a sus elevadas ventas pudo arrostrar diversos proyectos teatrales). Las reflexiones de Salaverría nos ofrecen una excelente panorámica de los debates internos del autor en un momento de cambio extraordinariamente interesante. Si bien sus ideas muestran una mentalidad anclada en antiguas concepciones sobre la creación, su trayectoria profesional es la de un moderno hombre de letras. 


\title{
RESUMEN
}

José María Salaverría y la profesionalización del escritor, Raquel Sánchez García

Durante los primeros años del siglo XX se produjo una importante transformación en el mundo editorial español que afectó también a los escritores. Comenzó para ellos un proceso de profesionalización que les iba a permitir vivir de la literatura en sus distintas manifestaciones: el periodismo, los libros, el teatro, etc. José María Salaverría es un buen ejemplo de la nueva situación del escritor porque desarrolló su actividad en este nuevo contexto siendo perfectamente consciente de ello. Además, dedicó muchas páginas a reflexionar acerca del papel del escritor en el mercado editorial y, en general, en la sociedad, considerando su actividad tanto desde el punto de vista del profesional como del intelectual.

Palabras clave: Historia de la edición. Escritores. Sociología del mundo literario. Intelectuales

\begin{abstract}
An important change took place in the Spanish publishing market during the first years of 20th century. The writers were highly affected by this change because they began to live off literature working as authors of plays and novels and writing in newspapers. In short, they became professionals of writing in a contemporary meaning. José María Salaverría is a good example. He worked in this context and he knew how important the new situation was for the authors. Furthermore, he wrote a lot of pages thinking about writes' role in the modern society and in the Spanish publishing market taking into account their activity as professionals and intellectuals.
\end{abstract}

Key words: Publishing history. Writers. Sociology of Literary World. Intellectuals. 